\title{
EFECTOS ECONÓMICOS Y PSICOLÓGICOS DE LA LATITUD
}

\author{
ECONOMIC AND PSYCHOLOGICAL EFFECTS OF LATITUDE
}

\author{
FEDERICO R. LEÓN ${ }^{1}$ \\ León \& Bustamante Consultores, Lima, Perú \\ (RECIBID EL 02/1/2012-AcEPTADO 5/12/2012
}

\begin{abstract}
RESUMEN
La riqueza de las naciones y la educación de las poblaciones crecen con la distancia al ecuador. El impacto de la latitud que se ve en el Perú abarca además los deseos de fertilidad y poder doméstico de la mujer y la salud mental de la población general. Este artículo resume dichos hallazgos y evalúa las teorías económicas formuladas para explicar la relación latitudriqueza a partir de la temperatura y diseminación cultural, así como las evolucionarias, que consideran diferencias raciales en inteligencia y personalidad. El artículo presenta como alternativa una teoría peruana reciente, basada en la influencia contemporánea de la radiación ultravioleta y la vitamina $\mathrm{D}$, que da cuenta de la evidencia con mayor parsimonia y tiene importantes implicancias prácticas.
\end{abstract}

Palabras clave: latitud, riqueza, evolución, radiación ultravioleta, inteligencia

\begin{abstract}
The nations' wealth and their population's education increase with distance from the equator. The impact of latitude seen in Peru additionally encompasses women's fertility desires and domestic power and the general population's mental health.This article summarizes such findings and assesses the economic theories formulated to explain the latitude-wealth linkage considering temperature and cultural dissemination, as well as evolutionary theories, which point to racial differences in intelligence and personality. The article presents an alternative, recent Peruvian theory based on the contemporary influence of ultraviolet radiation and vitamin $\mathrm{D}$ which accounts for the evidence with greater parsimony and has important practical implications.
\end{abstract}

Keywords: latitude, wealth, evolution, ultraviolet radiation, intelligence 


\section{INTRODUCCIÓN}

El análisis de datos de encuestas nacionales hechas a gran escala reveló hace más de un cuarto de siglo la variación norte-sur del deseo de hijos (León, 1984, 1986) y el uso de sustancias psicoactivas (León, 1987). Investigaciones subsecuentes realizadas con criterios geográficos y analíticos más sofisticados demostraron que la latitud también influía sobre el poder doméstico de la mujer (León, 2011, 2012a). Las teorías económicas y evolucionarias sobre la influencia de la latitud que prevalecen en la literatura norteamericana y europea no podían explicar enteramente los hallazgos nacionales. El autor formuló entonces una teoría para dar cuenta de ellos (León, 2012a) que llevó a la predicción y confirmación de que la violencia doméstica variaba positivamente con la latitud absoluta (León, 2012b) y permitió explicar la influencia de la latitud sobre la riqueza de los hogares y nivel educativo de la mujer en el Perú (León, 2012c).En este artículo se presenta la teoría propuesta después de describir los estudios peruanos que la demandaban y evaluar las teorías alternativas.

\section{ESTUDIOS PERUANOS}

\section{Deseo de Hijos}

Hacia 1983, el Instituto Nacional de Estadística distinguía solo las regiones políticas norte, centro, sur, y oriente. Estudios basados en la Encuesta Nacional de Prevalencia de Anticonceptivos de ese año indicaron que tanto el deseo de tener hijos de las mujeres (Morales, 1983) como su conocimiento de métodos anticonceptivos (Alcántara, 1983) crecían de sur a centro y de centro a norte en el Perú. En un análisis de la base de datos de esa encuesta, León (1984) confirmó la presencia de un crecimiento sur-centro-norte del deseo de hijos por parte de las mujeres casadas tanto en la costa como en la sierra peruanas manteniendo constantes el tamaño de la familia y la edad, la educación, y el trabajo de la mujer. León (1986) constató lo mismo para el caso de las mujeres solteras en otro estudio. Para explicar el fenómeno, conjeturó que la mujer del sur se distinguía por un afán mayor de independencia y desarrollo personal, mientras que la del norte estaría más gobernada por expectativas tradicionales de rol, según las cuales corresponde a la mujer dedicarse a la reproducción y el cuidado de los niños. Además, para explicar la distribución del conocimiento de anticonceptivos, sugirió que la mujer del norte podría tener mayor interés erótico, lo cual parecía consistente con el hallazgo de una mayor cantidad de cerámicos pre-hispánicos de contenido sexual explícito provenientes del norte que del centro o sur del Perú en la colección examinada por Kauffmann-Doig (1979).

\section{Uso de Sustancias}

El siguiente hallazgo concernía a la prevalencia de vida y uso actual de alcohol, tabaco y hoja de coca, que crecían en sentido opuesto, es decir, de norte a sur, con excepción del uso actual de alcohol en la costa, según análisis efectuados por León (1987) en las tablas de resultados de Druguse and abuse in Peru: An epi- 
demiological investigation of drugs in urban Peru (Jutkowitz et al., 1986). Para reconciliar este hallazgo con la interpretación geográfico-psicosocial previamente expuesta, se propuso una explicación según la cual las madres más independientes, entretenidas en trabajos fuera de casa y aspiraciones de desarrollo personal, causarían en sus hijos ciertas carencias afectivas que se expresarían luego, en su juventud y adultez, en un mayor consumo de sustancias psicoactivas. Dado que habría más mujeres independientes en el sur, cabría esperar mayor consumo de sustancias psicoactivas por sus hijos (León, 1987).

\section{Poder Doméstico}

El autor retomó el tema al cabo de 24 años, aprovechando la inclusión de variables clave en la Encuesta Continua de Demografía y Salud Familiar Perú 2004-2008 conducida por el Instituto Nacional de Estadística e Informática y ORC Macro. Los cuestionarios tenían un juego de ítems sobre el papel de la mujer en la toma de decisiones económicas del hogar que permitía distinguir su autonomía (toma de decisiones por su cuenta) de su participación en las decisiones con el marido (decisiones conjuntas) y su exclusión de las decisiones (desempoderamiento). En la Figura 1 se puede ver las diferencias que existen entre los departamentos más septentrionales y más meridionales de la costa, sierra, y selva peruanas respecto a quién toma las decisiones sobre las grandes compras para el hogar. La encuesta también introdujo mediciones GPS (Global Positioning System), de las cuales la más importante es la coordenada de latitud, que ofrece información exacta sobre la distancia entre el conglomerado tocado por la encuesta y la línea ecuatorial, una medición mucho más precisa que la tricotomía norte-centro-sur usada por León (1984, 1986, 1987). Ello facilitó además la prueba de hipótesis al interior de la selva, región natural omitida en los estudios iniciales porque el Instituto Nacional de Estadística de entonces no diferenciaba puntos al interior de esa región o cualquier otra. La hipótesis de una mayor autonomía de la mujer sureña versus mayor sometimiento tradicional al marido por la norteña fueron confirmados por los resultados de análisis logísticos multinomiales, que revelaron un crecimiento significativo de norte a sur del control de la mujer sobre las decisiones adquisitivas hogareñas y, especialmente, sobre el ingreso del cónyuge en las tres regiones naturales del Perú, tanto en grandes ciudades como en pueblos y en el campo. Estas relaciones no se explicaban por variables correlacionadas, como la etnicidad indígena, poder material-informacional de la mujer, diferencia de edad con el marido, o que trabajara por dinero (León, 2011).

Para replicar los hallazgos en una muestra distinta y con mayor rigor, León (2012a) apeló a una base de datos anterior, la Encuesta de Demografía y Salud Perú 2000, en la que realizó los análisis utilizando un sistema geográfico más desarrollado, el de las eco regiones de Brack (1983), que se grafica en la Figura 2. La Figura 3 presentalos principales resultados. El poder doméstico de la mujer crece significativamente en todas las regiones de norte a centro y de centro a sur, mientras que el deseo de hijos decae en esa misma dirección, independientemente de los efectos de otras 14 variables geofísicas y sociales (León, 2012a). 


\section{Violencia Doméstica}

Para evaluar una segunda área de la salud mental, la de la violencia familiar, León (2012b) analizó respuestas de 12,604 mujeres de la Encuesta Demográfica y de Salud Familiar Perú 2000. Quería determinar si la violencia física y psicológica ejercida por esposos y padres aumentaba con la distancia al ecuador. Los efectos de la latitud fueron consistentes con lo esperado en el desierto del Pacífico, la estepa serrana, la puna, y la ecoregión yunga, no así en la Amazonía. Lo que aparece en la Figura 4 son las medias brutas y las ajustadas por los efectos de otras variables.

\section{Riqueza y Educación}

En el estudio del 2011 de la Encuesta 2004-08, León había descubierto que la riqueza del hogar y la educación de la mujer crecían de norte a sur. Para poner a prueba la robustez del hallazgo utilizó la Encuesta del 2000. Confirmó que los activos del hogar crecían sistemáticamente de norte a sur en el desierto del Pacífico, la puna, la eco región yunga, y la Amazonía, especialmente en ámbitos rurales, mientras que la educación de la mujer lo hacía en las tres primeras. En ese estudio se omitió la sierra esteparia considerando su pequeño tamaño de muestra. Ni la temperatura ni otras 14 variables geofísicas y sociales daban cuenta de los efectos, aunque el poder doméstico de la mujer los explicaba en la ecoregión yunga (León, 2012c).La Tabla 1 exhibe uno de los resultados.

\section{TEORÍAS ECONÓMICAS}

Los hallazgos peruanos son consistentes con los de economistas europeos y norteamericanos quienes han reportado que la latitud absoluta predice la productividad del trabajador (Hall \& Jones, 1999), la intensidad del cultivo agrícola (Masters \&McMillan, 2000), el crecimiento económico (Cinyabuguma\&Putterman, 2011), el producto interno bruto per cápita (Bleaney\&Dimico, 2010; Gallup, 2000; Lynn, 2009a; Masters\&McMillan, 2000; McArthur\&Sachs, 2001; Olsson\&Hibbs, 2005; Ram, 1999; Sachs, 2000), y el producto por celda geográfica de un grado de latitud por uno de longitud (Nordhaus\&Chen, 2009).

\section{Efectos del Clima}

El rendimiento agrícola de todos los cultivos mayores es más bajo en los trópicos que en las regiones frías porque la alta temperatura y la humedad causan la rápida descomposición de la materia orgánica del suelo, robándole nutrientes así como la estructura necesaria para absorber fertilizantes y demorar la erosión. Más aún, mientras que la nieve invernal de las regiones temperadas mata patógenos y parásitos, la ausencia de temperaturas bajo cero en los trópicos facilita el desarrollo de un número mayor de pestes agrícolas y animales; enfermedades tropicales como la malaria o paludismo son endémicas y reducen la productividad laboral (Bhattacharyya, 2009; Bloom,Sachs,Collier, \&Udry, 1998; Carstensen\&Gundlach, 2006; Gallup \&Sachs, 2000; Gallup, Sachs, \&Mellinger, 1999; Sachs, 2003; Sachs\&Melaney, 2002). Así, la dicotomía de climas tropical versus temperado 
y/o la temperatura y/o el número de días con hielo al año como variables continuaspredicen una vasta gama de resultados económicos (Bhattacharyya, 2009; Bleaney\&Dimico, 2010; Gallup et al., 1999; Gutierrez, 2002; Masters \&McMillan, 2000; Masters \&Wiebe, 2000;McArthur\&Sachs, 2001; Mellinger, Sachs, \& Gallup., 1999; Nordhaus, 2006; Nordhaus et al., 2006; Nordhaus\&Chen, 2009; Olsson\&Hibbs, 2005; Sachs, 2000).

Pero el clima tiene una capacidad limitada para dar cuenta de la evidencia. La temperatura y otras variables geofísicas -que no incluyeron a la radiación ultravioleta- solo explicaron el $50 \%$ de la varianza del producto atribuible a la latitud alrededor del globoen el estudio de NordhausyChen (2009) y el caso del África sub-Sahariana desafió el rol del clima como causa, pues regiones tropicales similares a la sub-sahariana en otras partes del mundo exhibían mayor producto. Este fue el caso del noreste de Brasil, el norte de Australia y el sur de la India.El clima tampoco da cuenta de ciertos hallazgos en el Perú. Aunque en este país la temperatura exhibe fuertes correlaciones bivariadas negativas con la riqueza, sus impactos se desvanecen cuando la latitud entra en el modelo econométrico (véase la Tabla 1). Más aún, los efectos de la temperatura sobre la riqueza devienen en positivos en las frías alturas por encima de los $2,500 \mathrm{msnm}$. Y el clima no explica los efectos más fuertes de la latitud sobre la riqueza y educación encontrados en la costa desértica y las alturas andinas que en la región amazónica (León, 2012c). $\mathrm{Ni}$ en el desierto del Pacífico ni en la puna está presente el clima tropical que afecta a la agricultura y salud.

\section{Cultura e Instituciones}

La cultura (tecnología, confianza interpersonal, ética social) einstituciones (imperio de la ley, derechos de propiedad, apertura de mercados) proporcionan interpretacionesalternativas (véase Nunn, 2009). Hall y Jones (1999) atribuyeron los efectos de la latitud absoluta sobre el rendimiento del trabajador a la diseminación mundial de buenas instituciones y políticas gubernamentales desde Europa Occidental. Se puede ver esta influencia como un giro reciente de las interacciones entre geografía e historia que abordó Diamond (1997) teniendo en cuenta la orientación longitudinal de Eurasia y la latitudinal de África y América. Con anterioridad a tiempos modernos, la difusión cultural fue facilitada por contactos este-oeste a través de climas constantes (como en Eurasia), pero era difícil en contactos norte-sur a través de climas diversos (como en África y América). Olsson y Hibbs (2005) han fortalecido este punto de vista al mostrar que diferencias iniciales en dotaciones biogeográficas y geográficas dan cuenta ampliamente de los tiempos diferentes de la transición neolítica desde un estilo de vida nómade de cazadores y recolectores hasta la agricultura sedentaria y al demostrar que tales tiempos explican las diferencias en riqueza de 1 a 100 que existen actualmente entre las naciones. En la perspectiva cultural, el estatus económico relativo del África sub-Sahariana en los trópicos puede entenderse por la colonización portuguesa del noreste brasileño, la inmigración británica en el norte de Australia, y la localización del sur de la India en la encrucijada del mundo antiguo, conectando el Mediterráneo con el Extremo Oriente (ver Putterman\&Weil, 2010). 
Sin embargo, la calidad de las instituciones de nuestros días solo da cuenta de una parte menor de las diferencias actuales en prosperidad (Olsson\&Hibbs, 2005; Nunn, 2009) y la teoría de la difusión cultural es incapaz de explicar el vínculo latitud-riqueza observado dentro de losEstados Unidos (Ram,1999), China (Demurger et al., 2002), Brasil (PNUD Brasil,2005), Italia (Lynn, 2009a), y el Perú (León 2012c). El que ha hecho un esfuerzo por interpretar el efecto intra-país de la latitud es Lynn (2009a), quien atribuye la mayor pobreza del sur italiano a las prevalencia allí de genes mediterráneos y nor-africanos, versus genes nórdicos en el norte de Italia. Pero no existe una teoría cultural capaz de dar cuenta de los efectos de la latitud sobre la riqueza en los cinco países, a los que habría que añadir la candente zona del Euro como una unidad geográfica mayor, donde la productividad del trabajador alemán es 40 veces mayor que la del griego. Peor aún, en el caso del Perú la teoría cultural predeciría mayor riqueza en el norte que en el sur del país considerando la mayor presencia indígena en el sur a juzgar por la distribución geográfica del quechua y aimara (Knapp, 1987), cuando en realidad ocurre lo contrario.

\section{Teorías Evolucionarias}

Diferente es el caso de las teorías evolucionarias. Varios psicólogos arguyen que la riqueza de una nación depende de su capacidad tecnológica y, por ende, del cociente intelectual (CI) genéticamente determinado de su población. Pero es mejor hablar de g que de CI, porque g es un concepto más amplio. $\mathrm{g}$ - la habilidad de razonar deductiva o inductivamente, pensar abstractamente, usar analogías, sintetizar información, y aplicarla a nuevos dominios - no sólo se expresa en el CI sino también en tests educacionales como las pruebas PISA, TIMMS, y PIRLS (Rindermann, 2007). g se relaciona positivamente con la riqueza, tanto comparando países entre sí (v.g., Lynn \&Mikk, 2007;Rindermann, 2008) como comparando estados dentro de los Estados Unidos (Kanazawa, 2006) o regiones en Italia (Lynn, 2009a).

\section{El rol del Frío}

Fuertes relaciones ocurren entre g y raza. Pero la raza es realmente solo un sucedáneo de la latitud, puesto que las comparaciones generalmente oponen a las poblaciones de piel clara de regiones temperadas versus gentes de piel oscura originadas en tierras tropicales (Díaz, Sellami, Infanzón, Lanzón, \& Lynn, 2012; Kanazawa, 2008; Lynn, 2009a; Lynn \&Vanhanen, 2006; Rushton\& Jensen, 2005; Templer\&Arikawa, 2006). Como la piel humana (Jablonski, 2004), ciertas características psicológicas contemporáneas parecen ser resultado de adaptaciones evolutivas (Buss, 2004). Así, en una perspectiva evolucionaria, Rushton (1985) y Lynn (1991) han dado cuenta de la g superior de europeos y orientales asumiendo que las demandas cognitivas planteadas por la necesidad de sobrevivir el frío de las altas latitudes representaron una oportunidad de selección natural según la inteligencia. Es decir, g sería mayor entre poblaciones enraizadas en latitudes altas porque el frío de sus tremendos inviernos habría hecho que murieran pronto y no pudieran pasar sus genes al futuro quienes no podían anticipar la nieve y trabajar 
hábilmente preparándose para enfrentarla. Ello implica que el frío ancestral podría explicar las diferencias presentes en prosperidad vistas entre África sub-sahariana y regiones tropicales más ricas: los europeosy chinos no solo transportaron cultura cuando se mudaron a Brasil, Australia, Malasia o Singapur, sino también genes influidos por adaptaciones pre-históricas al frío.

Para entender el caso del Perú en esta perspectiva habría que tomar en cuenta que Homo sapiens s. cruzó el estrecho de Behring hace 20,000 años y llegó a Chile hace 14,000 años. Como quiera que la última Edad de Hielo terminó recién hace 11,400 años, Homo sapiens s. vivió en un Perú mucho más frío que el actual durante unos 3,000 años (véase Forster, 2004) y entonces pudo producirse la selección natural que habría causado una relación positiva entre latitud absoluta y riqueza vía el desarrollo de la inteligencia, con excepción de las regiones más cálidas. Por ejemplo, las diferencias de temperatura entre Tacna y Chiclayo habrían sido mucho mayores que en la actualidad. Esto puede parecer ciencia-ficción, pero no lo es, pues algunas de sus implicancias son verificables empíricamente. Por ejemplo, comparando resultados de las pruebas PISA y encontrando que las diferencias latitudinales son mayores en el desierto del Pacífico, la sierra esteparia y la puna, regiones donde el frío pudo establecer diferencias genéticas al ser mayor en el sur que en el norte, que en la Amazonía, donde el frío probablemente nunca llegó a alcanzar significación evolucionaria. León (2012c) atribuyó a la migración longitudinal desde la puna las significativas relaciones observadas entre latitud y riqueza y educación en la contigua yunga.

\section{Las Estrategias r/K y la Altura}

La teoría evolucionaria trasciende el frío. Rushton $(1985,2000)$ imaginó que el ambiente más predecible de los climas temperados, con estaciones muy diferenciadas que recurren año tras año, promovió una estrategia reproductiva $\mathrm{K}$, caracterizada por la restricción sexual y el cuidado paterno de la prole, en contraste con la estrategia $\mathrm{r}$ de los climas tropicales, caracterizada por altas tasas reproductivas y escaso cuidado de los niños. La estrategia K promovería el desarrollo de mayores habilidades cognitivas y rasgos de personalidad más adaptativos. Para explicar el mayor éxito intelectual de los orientales (chinos, japoneses, coreanos) que los europeos, formuló un continuo racial Negroide-Caucasoide-Mongoloide y asumió que estas razas representaban tres estadios del desarrollo de la humanidad.

Una teoría más reciente es la de Kanazawa $(2004,2010)$, según quien g se desarrolla cuando un problema evolucionariamente novedoso desafía la sobrevivencia. Por "evolucionariamente novedoso" Kanazawa entiende los problemas que no estuvieron presentes en la sabana del África sub-sahariana ancestral, es decir, el hábitat en el que apareció Homo sapiens s.hace unos 130,000 años. Transcurrieron decenas de miles de años sin que abandonara la sabana; en esa época ya estaba desarrollado el cerebro humano con su arquitectura presente. Entre lo que hubo de evolucionariamente novedoso para el hombre de la sabana, el frío es lo que ha atraído la atención de los psicólogos evolucionarios, pero eso no es lo único nuevo que encontró Homo sapiens s al salir de ella. Aún antes de aban- 
donar África hace unos 60,000 años tuvo que lidiar con las alturas de Tanzania, Kenya, y Etiopía y probablemente allí respondió desarrollando su inteligencia. La riqueza en África esté asociada positivamente con ámbitos montañosos, donde los economistas predicen el resultado contrario, pues allí es más difícil la agricultura, la construcción,y las comunicaciones. Nunn y Puga (2009) han atribuido este fenómeno a que el terreno rugoso dificultó la penetración de los mercaderes de esclavos que destruían las comunidades nativas. Pero el terreno montañoso pudo representar una situación evolucionariamente novedosa, que facilitó la diferenciación genética de quienes tuvieron la habilidad de sacar provecho de esas tierras difíciles. Las culturas pre-hispánicas más avanzadas de América en términos de formación del estado se desarrollaron en las alturas de Perú y México. La altura ayuda a explicar el hallazgo de mayores efectos de la latitud sobre el alfabetismo y nivel de educación en la puna que en cualquier otra región peruana (León, 2012c). La latitud probablemente interactuó con la altura para diferenciar la inteligencia de los antiguos peruanos. Como la altura crece de norte a sur en el Perú, el frío es mayor en Puno que en Cajamarca no solo porque Puno está más al sur sino también porque está a mayor altura sobre el nivel del mar.

Entonces, la teoría evolucionaria explica los hallazgos relativos a las diferencias norte-sur en riqueza y educación observadas por León (2012c) en el Perú. La de la educación a partir del de g: los padres más inteligentes seguramente insisten más en la educación de sus hijos y los hijos inteligentes seguramente son capaces de adaptarse mejor a los requerimientos cognitivos de la escuela y permanecen más tiempo en el sistema educativo. La de la riqueza a partir de g y la educación. Sin embargo, los descubrimientos peruanos concernientes a la influencia de la latitud sobre sobre el consumo de sustancias psicoactivas (León, 1987) y la violencia familiar (León, 2012b) contradicen a la teoría de Rushton (1985). Según la teoría $\mathrm{r} / \mathrm{K}$, las latitudes absolutas más altas producen personalidades mejor ajustadas, y el consumo de sustancias y violencia familiar son indicadores negativos en este aspecto. Además, la teoría de Rushton concibe a la raza mongoloide como la más avanzada, sin tener en cuenta que, según su propio razonamiento, debería serlo la Amerindia, por representar la escisión genética más tardía (Forster, 2004; Henn, Cavalli-Sforza, \&Feldman, 2012). Lo mismo ocurre con el concepto de lo evolucionariamente novedoso. Kanazawa (2008) predijo que las poblaciones más distantes de África Oriental presentarían mayores niveles intelectuales. La gran base de datos en la que Rindermann (2007) integró resultados de tests de CI y pruebas educacionales PISA y otras indican que los países con población original de Oceanía o América están por debajo de orientales y europeos en g. No obstante estas limitaciones, las teorías evolucionarias de la latitud siguen vivas a causa de la ausencia de alternativas en la literatura internacional.

Teoría de la Radiación Ultravioleta y la Vitamina D

Una alternativa ha surgido recientemente en el Perú: León (2012a) concluyó que la variable causal por descubrir tenía que ser una hija de la latitud y, por lo tanto, hermana de la temperatura y la buscó hasta encontrarla. 


\section{RUV y Sexualidad}

La luz del sol siempre fue vista como fuente de vida y felicidad, pero los poetas no sabían que el origen de la vitalidad no provenía de la luz visible. Otra confusión es la del estereotipo peruano del ardor sexual de la mujer loretana, y selvática en general, atribuido frecuentemente a las altas temperaturas de la selva peruana. En realidad, la radiación solar contiene tres elementos: luz visible, que nos hace ver; rayos infrarrojos, que producen calor; y la radiación ultravioleta (RUV), que permite a la piel y retina fabricar vitamina $\mathrm{D}$. Al igual que los rayos infrarrojos y la luz visible, la RUV es más fuerte en la línea ecuatorial y disminuye con la cercanía a los polos debido al eje de rotación del planeta. De esta manera, los fotones ultravioleta para producir vitamina $\mathrm{D}$ están disponibles a lo largo de todo el año en los trópicos, pero a latitudes más altas, como Boston o la Patagonia, la piel y la retina no pueden fabricarla en el invierno (Diffey 2002; Engelsen, Brustad, Aksnes, \& Lund, 2007). Pese a la existencia de fuentes alternativas dietéticas como ciertos pescados y sus aceites, la conexión RUV-vitamina D es claramente pertinente a la sexualidad humana. La producción de testosteronay estrógeno declina de noviembrea abril en el hemisferio norte y comienza a incrementarse constantemente desde abril (van Anders, Hampson, \& Watson, 2006), afectando directamente la tasa de concepciones humanas (Cummings, 2007). Esto se debe atribuir a la disponibilidad de vitamina D con el cambio estacional. Una consecuencia de su deficiencia en ratas y ratones de laboratorio es una marcada reducción de la fertilidad de la hembra e incremento de sus fallas reproductivas, debido aparentemente a que las bajas cantidades de vitamina $\mathrm{D}$ no interactúan normalmente con su receptor en los ovarios (Jones, Strugnell, \& DeLuca, 1998). Se ha demostrado el rol regulatorio de la vitamina $\mathrm{D}$ en la síntesis de hormonas sexuales; parece que su acción en la bíosíntesis del estrógeno se explica parcialmente por el mantenimiento de la homeostasis del calcio (Kinuta et al., 2000). Como quiera que la acción de la vitamina D sobre la testosterona es sensible a variaciones en la RUV, ambos, la vitamina y la hormona presentan variaciones estacionales paralelas (Wehr, Pitz, Boehm, März, \& Obermayer-Pietsch, 2009). La combinación de toda esta evidencia le sugirió a León (2012a) que es la exposición más intensa y continua a la RUV en latitudes bajas lo que causa las tasas más altas de embarazo adolescente observadas en el sur de los Estados Unidos que en el resto de ese país (Finer\&Kost, 2011). La alta tasa de fertilidad en el África sub-sahariana comparada con la de otras regiones del globo es ampliamente conocida. Centro y Sudamérica no presentan los mismos niveles de fertilidad porque su gente aprendió a usar anticonceptivos en las últimas décadas. También tiene sentido en esta perspectiva la distribución geográfica de cerámicos amerindios con contenidos sexuales explícitos en el Perú (León, 1986).

\section{Rasgos de Personalidad}

León (2011) imaginó efectos de la latitud sobre la personalidad para explicar el deseo decreciente de tener hijos que se observa con la distancia al ecuador tanto entre mujeres peruanas casadas (León, 1984) como solteras (León, 1986). Este deseo expresaría una orientación sexual, rasgo de personalidad o dimensión in- 
terpersonal conocida como femineidad, calidez o amor, la cual crecería de sur a norte en el Perú como consecuencia de los efectos de la RUV sobre la diferenciación sexual (León, 2012a). Similar ha sido la interpretación de los efectos de la latitud sobre el poder doméstico de la mujer (León, 2011, 2012a). La asertividad un componente de la extraversión (Eysenck \& Eysenck, 1985; Goldberg, 1973), mayor entre hombres que mujeres a través de culturas (Costa, Terracciano, \&McCrae, 2001), explicaría la relación latitud-poder (León, 2011). Es decir, el hecho de que las hormonas sexuales hagan a los hombres más masculinos y dominantes y a las mujeres más femeninas y sumisas (McLean\& Anderson, 2009) explicaría la reducción que se observa en el poder doméstico de la mujer con la cercanía a la latitud 00 o 00'(León 2012a). Calidez/amor y dominio/asertividad han sido concebidos como dimensiones ortogonales por Bem (1974) y Wiggins (1979) y como opuestos la una al otro por Costa y McCrae (1993). Confirmando los efectos esperados de la latitud sobre la diferenciación sexual, las correlaciones que León (2012a) encontró entre el deseo de hijos y el poder doméstico de la mujer eran negativas en el norte del Perú y perdían significación estadística en el sur.

\section{Salud Mental}

La vitamina D influye en neurotransmisores como la dopamina y la serotonina (Cass, Smith, \&Peters, 2006); más aún, la testosterona aumenta la producción de dopamina entre hombres (Hull, Muschamp, \& Sato, 2004). Se conoce a la dopamina como el mensajero de la felicidad porque causa estados afectivos positivos (Ashby, Isen, \&Turken, 1999); a su turno, la serotonina tiene un rol específico en la patofisiología de la depresión (Owens \& Nemeroff, 1994). De aquí que la vitamina D parezca ser parte de la dinámica del desorden afectivo estacional, un síndrome atribuido al déficit de exposición a la luz solar en el invierno que se trata con terapia de luz (Rosenthal et al., 1984; Gloth, Alam, Bruce, \&Hollis, 1999). La alta prevalencia de depresión en países hambrientos de luz, como los escandinavos, no ocurre en Islandia, una excepción que se atribuye a la alta tasa de consumo de pescado rico en vitamina D por los islandeses (Magnusson, Axelsson, Karlsson, \& Oskarsson, 2000). Se ha encontrado en Finlandia que esta relación entre dieta y depresión es moderada por el sexo, masculino-femenino (Timonen et al., 2004). Mientras que los estudios epidemiológicos de la conexión vitamina D-depresión han producido resultados mixtos, altas dosis de suplementos de vitamina D consistentemente mejoran síntomas depresivos medios (Bertone-Johnson, 2009). Por estas razones, León (2012a) interpretó el uso incrementado de alcohol, tabaco, y hoja de coca del norte al sur del Perú (León, 1987) como un esfuerzo individual para lidiar con desórdenes afectivos causados por la exposición a una empobrecida RUV con el aumento de la latitud. Este argumento llevó a la predicción de una relación positiva entre latitud absoluta y otro indicador negativo de salud mental, la violencia familiar, y su confirmación en cuatro de cinco regiones peruanas estudiadas (León, 2012b). León (2012b) conjeturó que la excepción de la Amazonía podría deberse a excesos de RUV entre $\operatorname{los} 0^{\circ}$ y 50 de latitud sur o a interacciones entre las variables dependientes. Por ejemplo, el erotismo de la mujer selvática en el norte podría causar celos y violencia en el marido. 


\section{Inteligencia}

El supuesto de una menor disponibilidad de vitamina D, testosterona y estrógeno a altas latitudes tiene implicancias intelectuales debido a las menores tasas de fertilidad que suponen y el consecuente tamaño menor de las familias. De acuerdo a Zajonc y Markus (1975), las familias pequeñas producen hijos más inteligentes que las familias grandes porque el desarrollo intelectual del niño depende de efectos acumulativos del ambiente intelectual del hogar. Este consiste primariamente de la edad mental de los padres y hermanos. El ambiente intelectual del niño se empobrece con la existencia o añadidura de hermanos, y el impacto es mayor a edades más tempranas (Zajonc\&Bargh, 1980; Zajonc\&Mullally, 1997; Zajonc\&Sulloway, 2007).

En esta perspectiva es fácil explicar el efecto Flynn. Flynn (1987) demostró ganancias importantes en CI de una generación a otra. Ahora se sabe que, para las naciones que ya eran desarrolladas a principios del siglo XX, la tasa ha sido de 3 puntos de CI de ganancia por década. Esas ganancias ya pararon en Noruega y son cada vez menores en otros países desarrollados, pero comienzan a crecer con más fuerza en los países menos desarrollados, de manera que se calcula que hacia el año 2050 habrá un igualamiento mundial de la inteligencia (Nisbett et al., 2012). Las explicaciones que se han dado para entender el fenómeno son insatisfactorias. Flynn (2009) argumentó que la Revolución Industrial y, más recientemente, el desarrollo de una actitud científica y analítica en la población han producido los incrementos intelectuales, pero este argumento es rebatido por la demostración de impresionantes ganancias generacionales entre niños pre-escolares, lo que Lynn (2009b) ha atribuido a mejorías de la nutrición. La teoría de Zajonc sugiere una explicación muy sencilla del efecto Flynn: la inteligencia mundial crece porque las familias son cada vez más pequeñas gracias al uso de la anticoncepción moderna.

\section{Moderadores}

La producción de vitamina D no solo depende de la latitud, estación del año, y tiempo de exposición a ella. También intervienen moderadores como el ozono total, las nubes, los aerosoles, la reflectividad del suelo y la altura (Engelsen, Brustad, Aksnes, \& Lund., 2007; McKensey, Björn, Bais, \&Ilyasd, 2003). Mientras más alto uno sube, mayor será la exposición a RUV (Dahlback, Gelsor, Stamnes, \& Gjessing). Por otro lado, sin embargo, la altura tiene efectos negativos netos sobre la sexualidad, aparentemente debido al déficit asociado de oxígeno. La exposición a gran altura reduce la testosterona en plasma (Gonzales, Kaneku, \&Góñez, 1992) y la espermatogénesis (Gasco, Rubio, Chung, Villegas, \& Gonzales, 2003). Probablemente ocurren efectos semejantes con respecto a los niveles de estrógeno, pues la menarquía demora en aparecer (Gonzales \& Ortíz, 1994) y se acelera la menopausia (Gonzales \& Villena, 1997). Wang, Cihlar, Wardle, y Kerr (2007) hallaron que latitud y altura, la latitud con mucho mayor fuerza, daban cuenta entre las dos del 95\% de la varianza de RUV en Estados Unidos, pero no consideraron la urbanización, que implica una vida bajo techo y consiguientemente menor exposición a fotones ultravioleta. Tal como se espera de la teoría de la RUV, las 
poblaciones urbanas del Perú, comparadas a las rurales,presentan niveles más altos de poder doméstico de la mujer (León, 2011, 2012a)y violencia familiar(León 2012b). Además, la influencia de la latitud sobre la riqueza y educación es mayor en ámbitos rurales que urbanos (León,2012c). Otro gran moderador es la Corriente de Humboldt, a causa de la niebla que trae sobre la costa peruana desde Lambayeque hasta Tacna. Por ejemplo, el 29 demayo del 2012 la RUV solo fue de 8.7 en Lima, menor que en La Paz (TuTiempo.net). De no haber sido por la niebla, habríamos tenido cerca de 11. Asimismo, datos de la Encuesta de Demografía y Salud Perú 2000 mostraron mayor violencia familiar neta -es decir, descontando los efectos de otras variables- en el desierto del Pacífico que en la Amazonía, dos regiones que están a la misma altura sobre el nivel del mar (León 2012b). Estos hallazgos son difíciles de explicar desde marcos teóricos alternativos.

Finalmente, hay que tener en cuenta la influencia de factores sociales en estos procesos, algunos de los cuales, a su turno, habrán sido influidos por la latitud. Estos efectos también son considerados por la teoría RUV sobre los efectos económicos y psicológicos de la latitud, como se puede ver en la Figura 5.

\section{Estatus e Implicancias}

Las teorías evolucionarias explican la distribución de la riqueza y la educación entre países. También lo hacen dentro de algunos países. Por ejemplo, la China del norte es mucho más fría que la del sur, y lo mismo ocurre en Italia. En ambos casos, buena parte de sus poblaciones probablemente está allí desde la última Edad de Hielo. Pero la teoría evolucionaria no puede explicar el hecho de que el norte de Estados Unidos sea más rico (Ram, 1999) y su gente más inteligente que la del sur (Kanazawa, 2006). Los europeos que llegaron a América del Norte ya sabían como lidiar con el frío y se hace difícil creer que los que se asentaron cerca a Canadá se hicieron más inteligentes que quienes poblaron el sur y la frontera de México porque los menos inteligentes de ellos murieron a causa de la baja temperatura. Más aún, la teoría evolucionaria de Rushton es contradicha por los hallazgos peruanos relativos a la salud mental (León, 1987; 2012b), pues la teoría r/K predice lo contrario de lo hallado en el Perú. Las teorías evolucionarias necesitarían numerosos supuestos para dar cuenta de la influencia de la latitud sobre el deseo de hijos y poder doméstico de la mujer. Uno de los principios supremos de la ciencia es el de la parsimonia, que obliga al científico a escoger la explicación más simple. Ninguna de las teorías evolucionarias explica la influencia de la latitud sobre el poder de la mujer y el deseo de hijos con la parsimonia con que lo hace la teoría de la RUV.

Esto no quiere decir, por supuesto, que la teoría de la RUV lo explique todo. Lo que la teoría aporta es simplemente uno de los factores que influyen sobre la riqueza del hogar, la educación de la mujer, su poder doméstico y deseo de hijos, y la salud mental de la población. Las ciencias sociales- y la psicología es una de ellas, lo mismo que la economía- asumen que cada fenómeno es multideterminado y lo máximo que pueden hacer por ahora es acercarse a estos fenómenos con enfoques probabilísticos. Además, la teoría necesita mayor soporte empírico. Este apoyo podría provenir de estudios en el Perú que 1. demuestren que el rasgo 
de femineidad/calidez/amor, adecuadamente medido, crece de sur a norte; 2 . que lo contrario ocurre con la asertividad de la mujer peruana como rasgo de personalidad, es decir, más allá de lo que implica para su poder doméstico; 3. que los puntajes de las pruebas PISA o el CI de la población crecen de norte a sur con prescindencia de otras influencias; 4. que todas estas relaciones ocurren también en otros países del hemisferio sur; 5. y que lo opuesto se observa en el hemisferio norte. Evidentemente, la mejor prueba se conseguiría midiendo directamente la RUV, pero la información satelital disponible requiere de traducciones a partir de información recogida por estaciones de SENAMHI a nivel del suelo que no son fácilmente asequibles.

No es necesario, sin embargo, esperar a que se concreten todas estas comprobaciones para ir derivando implicancias prácticas. Sachs (2000) sugirió posibles maneras de salir del subdesarrollo atribuible a la geografía, pero su visión solo cubría los desafíos planteados por la temperatura actual. La teoría de la RUV sugiere dos tipos de acción para lidiar con los efectos intelectuales de la latitud, es decir para igualar a los peruanos del sur y del norte o, mejor aún, para continuar desarrollando a todos los peruanos. Primero, la investigación contemporánea demuestra que se puede mejorar las habilidades mentales dentro del curso de vida de los individuos. Brinch y Galloway (2011) observaron el experimento natural que se creó en Noruega cuando se comenzó a exigir dos años extra de escolaridad después del grado séptimo; ellos encontraron que los efectos positivos sobre el CI eran sustanciales a los 19 años de edad. Cada año de escolaridad agrega un monto importante de CI (Ceci, 1991; Ceci \& Williams, 2007; Feng, Spence, \&Pratt, 2007; Hansen, Heckman, \& Mullen, 2004; Winship\&Korenman, 1997). Este factor cuantitativo de años de escolaridad, a su vez, seguramente es sinérgico con la educación que pone el foco en el desarrollo de habilidades intelectuales, creatividad, y fuerza moral de los estudiantes y no en la mera acumulación de conocimientos (Chetty et al., 2010; Herrnstein, Nickerson, Sanchez, \&Swets, 1986; Nisbettet al., 2012; Sternberg\& The Rainbow Project Collaborators, 2005).

De otro lado, el componente Zajonc de la teoría de la RUV implica que los programas de planificación familiar, al reducir el tamaño de la familia y, por ende, mejorar el ambiente intelectual hogareño para el niño, probablemente están causando efectos intelectuales positivos en todo el mundo. (Considérese la política reproductiva oficial china de un niño.) Desafortunadamente, la planificación familiar ha tenido una historia accidentada en el Perú. El régimen del presidente Fujimori (1990-2000) la abordó como una herramienta clave para el desarrollo socioeconómico del país. Una ley aprobada en 1995 hizo disponibles los servicios de esterilización para todas las mujeres sobre una base voluntaria. En el pasado, este método anticonceptivo solo era legal para mujeres que presentaran condiciones de salud extremas. El Ministerio de Salud recibió la instrucción de prepararse para responder a una demanda embalsada de esterilizaciones. Buscando efectividad, el Programa Nacional de Planificación Familiar demandó que todos los proveedores de planificación familiar del Ministerio proporcionaran protección anticonceptiva a un número especificado de parejas cada mes (León, Monge, Zumarán, García, 
\& Ríos, 2001, p. 33). Es probable que los proveedores se hayan sentido inducidos a ejercer presión sobre las mujeres que no solicitaban métodos anticonceptivos pese a tener un riesgo reproductivo, es decir, mujeres de una cierta edad y con un número dado de partos previos o ciertas condiciones médicas, a quienes habrían inducido a esterilizarse. El personal de salud tiende al autoritarismo y cree que sabe lo que le conviene al paciente aunque el paciente no crea lo mismo. El ministerio probablemente sobreestimó la demanda de esterilizaciones porque la calculó sobre la base del número de mujeres con riesgo reproductivo, no el de mujeres que querían esterilizarse, de manera que no tenía cómo saber cuándo se había satisfecho la demanda real de esterilizaciones y ya no era necesario seguir presionando a su personal para atenderla. Fueron documentados casos de servicios de esterilización dados con baja calidad y varias muertes fueron atribuidas a ellos. En 1997, grupos de derechos humanos, activistas religiosos y feministas criticaron severamente al Ministerio, acusándolo de ejercer coerción sobre las mujeres para que se esterilizaran. Atendiendo a una preocupación del Senado norteamericano respecto al posible uso de fondos norteamericanos de ayuda internacional por parte de programas coercitivos, la oficina de Lima del Population Council condujo investigaciones exhaustivas a nivel nacional. En una de ellas se encontró que la calidad de los servicios de planificación familiar que ofrecía el Ministerio de Salud estaba lejos de ser satisfactoria (León, 1999) y en la siguiente que al $2.4 \%$ de las mujeres se les había ofrecido incentivos o amenazado para que adopten la planificación familiar (León y García,2000). Habiendo identificado una necesidad de proporcionar a los proveedores nuevas herramientas técnicas que aseguraran un servicio eficaz dirigido a satisfacer hasta donde fuese posible las necesidades objetivas de salud reproductiva de las mujeres sin violar su voluntad, el autor diseñó y puso a prueba a nivel nacional una Estrategia de Consejería Balanceada que fortalecía el rigor de los servicios (León, Ríos, Zumarán, \&Bratt, 2003, León, Ríos, \&Zumarán, 2005). Sin embargo, tuvo que irse a perfeccionar esta herramienta en Guatemala, donde se ha convertido en el modelo nacional oficial de atención en planificación familiar (León, Brambila, et al., 2005), para pasar después a Sudáfrica y otros países africanos (León, Vernon, Martin, \& Bruce, 2008), porque el gobierno conservador del presidente Toledo en el área de la salud (2001-2006) virtualmente desmanteló el programa de planificación familiar del Perú. Los gobiernos siguientes han optado por mantener un perfil bajo en esta área.

El componente Zajonc de la teoría de la RUV sugiere que la planificación familiar debe, nuevamente, ser formulada como una prioridad nacional, esta vez como una estrategia para mejorar la inteligencia de las futuras generaciones de peruanos, además de prevenir el perjudicial embarazo adolescente y atender el derecho de las mujeres a acceder a una anticoncepción efectiva cuando lo quieran.

\section{CONCLUSIONES}

La evidencia revisada permite concluir que la teoría de la radiación ultravioleta formulada para explicar la influencia de la latitud sobre variables económicas y psicológicas es más completa y parsimoniosa que las teorías económicas o evo- 
lucionarias. Sin embargo, presenta vacíos como la falta de verificación directa mediante la medición de la radiación ultravioleta y otros, que el trabajo teórico e investigación empírica del futuro deben subsanar. La teoría sugiere que la planificación familiar favorece el desarrollo humano de las poblaciones.

\section{REFERENCIAS BIBLIOGRÁFICAS}

Alcántara, E. (1983). Conocimiento de métodos anticonceptivos. En Instituto Nacional de Estadística, Aspectos demográficos y prevalencia de anticonceptivos. Resultados de la Primera Encuesta Nacional de Prevalencia de Anticonceptivos. Lima: Autor.

Ashby, F. G., Isen, A. M., \&Turken, U. (1999). A neuropsychological theory of positive affect and its influence on cognition. Psychological Review, 106,529-550.

Bhattacharyya, S. (2009). Root causes of African underdevelopment. Journal of African Economies, 18, 745-780.

Bem, S. L. (1974). The measurement of psychological androgyny. Journal of Consulting and Clinical Psychology, 42, 115-162.

Bertone-Johnson, E. R. (2009). Vitamin D and the occurrence of depression: Causal association or circumstantial evidence? Nutrition Reviews, 67, 481-492.

Bleaney, M.,\&Dimico, A. (2010). Geographical influences on long-run development. Journal of African Economies, 19, 635-656.

Bloom, D. E., Sachs, J. D., Collier, P., Udry, C. (1998). Geography, demography, and economic growth in Africa. Brookings Papers on Economic Activity, 2, 207-295.

Brack, A. (1983). El ambiente en que vivimos. Lima: Editorial Salesiana.

Brinch, C. N., \& Galloway, T. A. (2011). Schooling in adolescence raises IQ. Oslo: Research Department of Statistics Norway.

Buss, D. M. (2004). Evolutionary psychology: The new science of the mind, 2nd. Ed. Boston: Pearson Education Inc.

Carstensen, K., \&Gundlach, E. (2006).The primacy of institutions reconsidered: Direct income effects of malaria prevalence. The World Bank Economic Review, 20, 309-339.

Cass, W. A., Smith, M. P, \&Peters, L. E. (2006).Calcitriol protects against the dopamineand serotonin-depleting effects of neurotoxic doses of methanphetamine. Annals of the New York Academy of Sciences, 1074, 261-271.

Chetty, R., Friedman, J. N.,Hilger, N., Saez, E., Whitmore Schanzenbach,D., \& Yagan, D. (2010). How does your kindergarten classroom affect your earnings? Evidence from Project Star. Cambridge, MA: National Bureau of Economic Research.

Ceci, S. J. (1991). How much does schooling influence general intelligence and its cognitive components? A reassessment of the evidence. Developmental Psychology, 27, 703-722.

Ceci, S. J., \&Williams, W. M. (2007).Little g: prospects and constrains. European Journal of Personality, 21, 716-718. 
Cinyabuguma, M. M., \&Putterman, L. (2011).Sub-Saharan growth surprises: being heterogeneous, inland and close to the Equator doesn't slow growthwithin Africa. Journal of African Economies, 20, 217-262.

Costa Jr., P. T., \&McCrae, R. R. (1992). Revised NEO Personality Inventory (NEOPIR) and NEO Five Factor Inventory (NEO-FFI) professional manual. Odessa, FL: Psychological Assessment Resources.

Costa Jr., P. T. Terracciano, A., \& McCrae, R. R. (2001).Gender differences in personality traits across cultures: Robust and surprising findings. Journal of Personalityy and Social Psychology, 81, 322-331.

Cummings, D. R. (2007).Additional confirmation for the effects of environmental light intensity on the seasonality of human conceptions. Journal of Biosocial Science, 39, 3, 383-396.

Dahlback, A., Gelsor, N., Stamnes, J. J., \&Gjessing, Y. (2007). UV measurements in the 3000-5000 m altitude region in Tibet. Journal of Geophysical Research, 112, 3-13.

Démurger, S., Sachs, J. D., Woo, W. T., Bao, S., Chang, G., \& Mellinger, A. (2002).

Geography, economic policy, and regional development in China. Asian Economic Papers, 1, 146-197.

Diamond, J. (1997).Guns, germs, and steel. New York: W. W. Norton \& Company. Díaz, A., Sellami, K., Infanzón, E., Lanzón, T., \& Lynn, R. 2012. A comparative study of general intelligence in Spanish and Moroccan samples. The Spanish Journal of Psychology, 15, 526-532..

Diffey, B. L. (2002). Sources and measurement of ultraviolet radiation. Methods, 28, 4-13.

Engelsen, O., Brustad, M., Aksnes, L., \& Lund, E. (2007). Daily duration of Vitamin D synthesis in human skin with relation to latitude, total ozone, altitude, ground cover, aerosols and cloud thickness. Photochemistry and Photobiology, 81, 1287-1290.

Eysenck, H. J., \&Eysenck, M. W. (1985). Personality and individual differences: A natural science approach. New York, NY: Plenum.

Feng, J., Spence, I., \& Pratt, J. (2007). Playing an action video game reduces gender differences in spatial cognition. Psychological Science, 18, 850-855.

Finer, L. B., \& Kost, K. (2011). Unintended pregnancy rates at the state level. Perspectives on Sexual and Reproductive Health, 43, 78-87.

Flynn, J. R. (1987). Massive IQ gains in 14 nations: What IQ tests reallymeasure. Psychological Bulletin, 101, 171-191.

Flynn, J. R. (2009). What is intelligence? Beyond the Flynn effect (enlarged paperback ed.). Cambridge, Inglaterra: Cambridge University Press.

Forster, P. (2004). Ice Ages and the mitochondrial DNA chronology of human dispersals: A review. Philosophical Transactions of the Royal Society. B. Biological Sciences, $359,255-264$. 
Gallup, J. L. (2000). Geography and socioeconomic development. Background paper examining the state of the Andean Region for the Andean Competitiveness Project. Disponible en: http://www.cid.harvard.edu/.

Gallup, J. L., \&Sachs, J. D. (2000). The economic burden of malaria, Harvard University Center for International Development Working PaperNo. 52.

Gallup, J. L., Sachs, J. D., \&Mellinger, A. (1999).Geography and economic Development. International Regional Science Review 22, 179-232.

Gasco, M., Rubio, J.,Chung, A., Villegas, L., \& Gonzales, G. F. (2003).Effect of high altitude exposure on spermatogenesis and epididymal sperm count in male rats. Andrologia, 35, 368-374.

Gloth III, F. M., Alam, W., Bruce, W., \& Hollis, B. W. (1999).Vitamin D vs. broad spectrum phototherapy in the treatment of seasonal affective disorder. Journal of Nutrition, Health and Ageing, 3, 5-7.

Goldberg, L. R. (1973). The structure of phenotipic personality traits. American Psychologist, 48, 26-34.

Gonzales, G. F., Kaneku, L., \&Góñez, C. (1992). Fisiología y patología de la reproducción en las grandes alturas. Acta Andina, 1, 3-16.

Gonzales, G. F., \&Ortíz, I. (1994).Age at menarche at sea level and high altitude in Peruvian women of different ethnic background. American Journal of Human Biology, 6, 674-640.

Gonzales, G. F., \&Villena, A. (1997). Age at menopause in central Andean Peruvian women. Menopause, $4,1$.

Gutierrez, L. (2002). Why is agricultural labour productivity higher in some countries than others? Agriculture Economics Review, 3, 58-72.

Hall, R. E., \& Jones, C. I. (1999). Why do some countries produce so much more output per worker than other countries? Quarterly Journal of Economics, 114, 83-116.

Hansen, K. T., Hechman, J. J., \& Mullen, K. J. (2004). The effects of schooling and ability on achievement test scores. Journal of Econometrics, 121, 39-98.

Henn, B. M., Cavalli-Sforza, L. L., \&Feldman, M. W. (2012). The great human expansion. Proceedings from the National Academy of Sciences of the United States, 109, 17758-17764.

Herrnstein, R. J., Nickerson, R. S., Sánchez, M. de, \&Swets, J. A. (1986). Teaching thinking skills. American Psychologist, 41, 1279-1289.

Hull, E. M., Muschamp, J. W., \& Sato, S. (2004). Dopamine and serotonin: influences on male sexual behavior. Physiology \& Behavior, 83, 2, 291-307.

Jablonsky, N. G. (2004). The evolution of human skin and skin color. Annual Review of Anthropology, 33, 585-623. 
Jones, G., Strugnell, S. A., \& DeLuca, H. F. (1998). Current understanding of the molecularactions of vitamin D. Physiological Reviews, 78, 1194-1231.

Jutkowitz, J. M., Arellano, R., Castro de la Mata, R., Davis, P. D., Elinson, J.,Jerí, F.R., et al. (1986). Drug use and abuse in Peru: An epidemiological investigation of drugs in urban Peru. Lima: Development Associates.

Kanazawa, S. (2004). The Savanna Principle. Managerial and Decision Economics, 25, 41-54.

Kanazawa, S. (2006).IQ and the wealth of states. Intelligence, 34, 593-600.

Kanazawa, S. (2008).Temperature and evolutionary novelty as forces behind the evolution of general intelligence. Intelligence, 36,99-108.

Kanazawa, S. (2010).Evolutionary psychology and intelligence research. American Psychologist, 65, 279-289.

Kauffmann-Doig, F. (1979). Sexual behavior in ancient Peru. Lima: Kompaktos.

Kinuta, K., Tanaka, H., Morikawe, T., Aya, K., Kato, S., \&Seino, Y. (2000).Vitamin $\mathrm{D}$ is an important factor in estrogen biosynthesis of both female and male gonads. Endocrinology, 141, 1317-1324.

Knapp, G. (1987). Linguistic and cultural geography of contemporary Peru.University of Texas at Austin Institute for Latin American Studies Paper N. ${ }^{\circ} 87-13$.

León, F. R. (1984).El eje fecundatorio norte-sur del Perú: Una interpretación psicológica. Revista de Psicología, 2, 95-111.

León, F. R. (1986). Factores psicosociales, psicoeconómicos, y psicosexuales en el eje fecundatorio norte-sur del Perú. En F. R.León (ed.), Psicología y realidad peruana: El aporte objetivo. Lima: Mosca Azul Editores, pp. 87-105.

León, F. R. (1987). Las drogas y las madres sureñas y norteñas: El eje psicoactivo nortesur del Perú. Socialismo y Participación, 37, 123-129.

León, F. R. (1999). Peru: Providers' compliance with quality of care norms. Lima: Population Council.

León, F. R. (2011). Latitud sur y control económico del hogar por la mujer peruana. Revista de Psicología, 29, 362-388.

León, F. R. (2012a). Una teoría psicobiogeográfica del poder doméstico de la mujer. Revista Peruana de Psicología y Trabajo Social, 1, 29-44.

León, F. R. (2012b). Ajuste de la violencia familiar a la teoría psicobíogeográfica de la salud mental. Revista de Psicología, enprensa.

León, F. R. (2012c).The latitudinal tilts of wealth and education in Peru: Testing them, explaining them, and reflecting on them. Economía, en prensa.

León, F. R., Brambila, C., De la Cruz, M., García Colindres, J., Morales, C., et al. (2005). Providers' compliance with the Balanced Counseling Strategy in Guatemala. Studies in Family Planning, 36, 117-126. 
León, F. R., \& García, I. (2000).Tiahrt Amendment violations in Peru: Incentives and threats to clients.Lima: Population Council.

León, F. R., Monge, R., Zumarán, A., García, I., \& Ríos, A. (2001).Length of counseling sessions and the amount of relevant information exchanged: A study in Peruvian clinics. International Family Planning Perspectives, 27, 28-33.

León, F. R., Ríos, A., \& Zumarán, A. (2005). Training x trainee interactions in a family planning intervention. Evaluation Review, 29, 576-590.

León, F. R., Ríos, A., Zumarán, A., \& Bratt, J. (2003).Perú: La estrategia de consejería balanceada. México, DF: Population Council.

León, F. R., Vernon, R., Martin, A., \& Bruce, L. (2008).The Balanced Counseling Strategy: A toolkit for family planning service providers. New York: Population Council.

Lynn, R. (1991). The evolution of race differences in intelligence. Mankind Quarterly, 32, 99-173.

Lynn, R. (2009a). In Italy, north-south differences in IQ predict differences in income, education, infant mortality, stature, and literacy. Intelligence, 38, 93-100.

Lynn, R. (2009b). What has caused the Flynn effect? Secular increases in the Development Quotients of infants. Intelligence, 37, 16-24.

Lynn, R., \& Mikk, J. (2007). National differences in intelligence and educational attainment. Intelligence, 36, 115-121.

Lynn, R., \& Vanhanen, T. (2006). IQ and global inequality. Athens, GA: Washington Summit Publishers.

MacArthur, J. W., \& Sachs, J. D. (2001).Institutions and geography: Comment on Acemoglu, Johnson and Robinson (2000). NBER Working Paper No. 8114.

MacLean, C. P., \&Anderson, E. R. (2009).Brave men and timid women? A review of the gender differences in fear and anxiety. Clinical Psychology Review, 29, 6, 496-505.

Magnusson, A., Axelsson, J., Karlsson, M. M., \&Oskarsson, H. (2000).Lack of seasonal mood change in the Icelandic population: Results of a cross-sectional study. American Journal of Psychiatry, 157, 2, 234-238.

Masters, W. A., \& McMillan, M. S. (2000). Climate and scale in economic growth. The Centre for the Study of African Economies Working Paper Series N. ${ }^{\circ} 123$.

Masters, W. A., \&Wiebe, K. D. (2000).Climate and agricultural productivity. Oxford, MA: Harvard University Center for International Developement.

McKensey, R. L., Björn, L. O., Bais, A., \&Ilyasd, M. (2003).Changes in biologically active ultraviolet radiation reaching the Earth's surface. Photochemichal and Photobiological Sciences, 2, 5-15.

Mellinger, A. D., Sachs, J. D., \&Gallup, J. L. (1999).Climate, water navigability, and economic development. Harvard University CID Working Paper N. ${ }^{\circ} 2$. 
Morales, T. (1983). Intenciones reproductivas. En Instituto Nacional de Estadística, Aspectos demográficos y prevalencia de anticonceptivos. Resultados de la Primera Encuesta Nacional de Prevalencia de Anticonceptivos. Lima: Autor.

Nisbett, R. E., Aronson, J., Blair, C., Dickens, W., Flynn, J., et al. (2012). Intelligence: New findings and theoretical developments. American Psychologist, 67, 130-159.

Nordhaus, W. D. (2006).Geography and macroeconomics: New data and new findings. Proceedings of the National Academy of Sciences of the United States, 103, 35103517.

Nordhaus, W. D. Azam, Q., Corderi, D., Hood, K., Makarova Victor, N., et al., (2006). The G-Econ database on gridded output: methods and data. Unpublished manuscript, Yale University.

Nordhaus, W. D., \&Chen, X. (2009).Geography: graphics and economics. The B. E. Journal of Economic Analysis \& Policy, 9, Iss. 2, Article 1.

Nunn, N. (2009). The importance of history for economic development. NBER Working Paper No. 14899.

Nunn, N., \&Puga, D. (2009).Ruggedness: the blessing of bad geography in Africa. NBER Working Paper No. 14918.

Olsson, O. \&Hibbs Jr., D. A. (2005).Biogeography and long-run economic development. European Economic Review, 49, 909-938.

Owens, M. J., \& Nemeroff, C. B. (1994). Role of serotonin in the pathophysiology of depression: Focus on the serotonin transporter. Clinical Chemistry, 40, 288-295. PNUD Brasil. (2005). Relatório de desenvolvimiento humano: Racismo, pobreza e violéncia. Brasilia: Programa das Nacoes Unidas para o Desenvolvimiento.

Putteran, L., \&Weil, D. N. (2010). Post-1500 population flows and the long-run determinants of economic growth and inequality. The Quarterly Journal of Economics, $125,1627-1682$.

Ram, R. (1999). Tropics and income: A longitudinal study of the U. S. states. Review of Income and Wealth, 45, 373-378.

Rindermann, H. (2007). The g-factor of international cognitive ability comparisons: The homogeneity of results in PISA, TIMSS, PIRLS and IQ-tests across nations. European Journal of Personality, 21, 667-706.

Rindermann, H. (2008). Relevance of education and intelligence at the national level for the economic welfare of people. Intelligence,36, 127-142.

Rosenthal, N. E., Sack, D. A., Gillin, J. C., Lewy, A. J., Goodwin, F. K., et al. (1984). Seasonal affective disorder: A description of the syndrome and preliminary findings with light therapy. Archives of General Psychiatry, 41, 1, 72-80.

Rushton, J. P. (1985). Differential K theory: The sociobiology of individual and group differences. Personality and Individual Differences, 6, 441-452.

Rushton, J. P. (2000). Race, evolution, and behavior: A life history perspective (3rd.ed.). Port Huron, MI: Charles Darwin Research Institute. 
Rushton, J. P., \& Jensen, A. R. (2005). Thirty years of research on race differences in cognitive ability. Psychology, Public Policy, and Law, 11, 235-294.

Sachs, J. D. (2000). Tropical underdevelopment.Center for International Development, Harvard University, Working Paper N. ${ }^{\circ} 57$.

Sachs, J. D. (2003). Institutions don't rule: direct effects of geography on per capital income, NBER Working Paper No. 9490.

Sachs, J. D., \&Melaney, P. (2002). The economic and social burden of malaria. Nature, $415,680-685$.

Sternberg, R. J., \&TheRaimbow Project Collaborators. (2005). The Rainbow Project: enhancing the SAT through assessments of analytical, practical, and creative skills. Intelligence, 34, 321-350.

Templer, D. I., \& Arikawa, H. (2006). Temperature, skin color, per capita income, and IQ: An international perspective. Intelligence, 34, 121-139.

Timonen, M., Horrobin, D., Jokelainen, J., Laitinen, J., Herva, A., et al. (2004). Fish consumption and depression: The Northern Finland 1966 birth cohort study. Journal of Affective Disorders, 82, 447-452. TuTiempo.net. (2012). Predicciones de clima. Bajado de http://tutiempo.net el 29 de mayo del 2012.

VanAnders, S. M., Hampson, E., \& Watson, N. V. (2006). Seasonality, waist-to-hip ratio, and salivary testosterone. Psychoneuroendocrinology, 31, 7, 895-899.

Wang, P., Li, Z., Cihlar, J, Wardle, D. I., \& Kerr, J. (2007). Validation of an UV invertion algorithm using satellite and surface measurements. Journal of Geophysical Research, 105, 5037-5048.

Wehr, E., Pitz, S., Boehm, B. O., März, W., \& Obermayer-Pietsch, B. (2009). Association of vitamin D status with serum androgen levels in men. Clinical Endocrinology, 73, 2, 243-248.

Wiggins, J. S. (1979). A psychological taxonomy of trait descriptive terms: The interpersonal domain. Journal of Personality and Social Psychology, 37, 395-412.

Winship, C., \& Korenman, S. (1997). Does staying in school make you smarter? The effect of education on IQ in The Bell Curve. En B. Devlin, S. E. Fienberg, D. P.

Resnick, \& K. Roeder (Eds.), Intelligence, genes, and success. New York: Springer.

Zajonc, R. B., \& Bargh, J. (1980). The confluence model: Parameter estimation for six divergent data sets on family factors and intelligence. Intelligence, 4, 349-361.

Zajonc, R. B., \& Markus, G. B. (1975). Birth order and intellectual development. Psychological Review, 82, 74-88.

Zajonc, R. B., \& Mullally, P. R. (1997). Birth order: Reconciling conflicting effects. American Psychologist, 52, 685-699.

Zajonc, R. B., \& Sulloway, F. J. (2007). The confluence model: Birth order as a withinfamily or between-family dynamic? Personality and SocialPsychology Bulletin, 33, 1187-1194. 


\section{Nota del Autor}

El autor es socio de León \& Bustamante Consultores. Versiones anteriores del manuscrito fueron presentadas en el Congreso Iberoamericano de Psicología (Lima, 7 de noviembre de 2012) y con ocasión del Aniversario de la Facultad de Psicología de la Universidad Nacional Mayor de San Marcos (10 de diciembre de 2012). Fondos para la preparación de este artículo fueron proporcionados por María Bustamante de León. El autor agradece a su esposa y socia, así como a Demographic and HealthSurveys por permitirle el acceso a sus bases de datos.

Tabla 1.

Coeficientes estandarizados de regresiones OLS del Puntaje de Riqueza del Hogar y Alfabetismo/ Educación de la Mujer sobre lalatitud y 14 covariables (A), temperatura y 14 covariables (B), y latitud, temperatura, y 14 covariables (C) en el Perú. Fuente: León, 2012c,

Tabla 3.1

\begin{tabular}{|c|c|c|c|c|c|c|}
\hline \multirow[b]{2}{*}{ Variables } & \multicolumn{3}{|c|}{ Puntaje de Riqueza del Hogar } & \multicolumn{3}{|c|}{ Alfabetismo/Educación } \\
\hline & $A$ & B & C & $A$ & B & C \\
\hline Latitude absoluta & & & $.324^{* * *}$ & & & $.227^{\star * *}$ \\
\hline Temperatura & $.32 y^{2 \pi *}$ & $-.179^{\star \star \star}$ & -.009 & .221 & $-.117^{\star * \star}$ & .001 \\
\hline Urbanización & .040 & $.320^{\star * *}$ & $.636^{* * *}$ & $\begin{array}{l}.340 \\
193 * * *\end{array}$ & $.127^{\star \star *}$ & $.349^{* * *}$ \\
\hline Latitud absoluta x urbanización & $\begin{array}{l}-.180^{* * *} \\
-.09 * * *\end{array}$ & $.198^{\star * *}$ & $-.178^{* * *}$ & $\begin{array}{l}-.193^{n n} \\
001\end{array}$ & $.070^{\star * \star}$ & $-.194^{* * *}$ \\
\hline Temperatura x urbanización & $\begin{array}{l}-.092 \\
-079^{* * *}\end{array}$ & $.078^{\star \star \star}$ & $-.082^{\star * *}$ & .001 & $.112^{\star \star *}$ & -.001 \\
\hline Longitud oeste & $-151^{* * *}$ & $-.039^{* * *}$ & $-.079^{\star * \star}$ & -.001 & $.027^{* *}$ & -.001 \\
\hline Altura & $-151 *$ & $-.146^{* * *}$ & $-.152^{\star \star \star}$ & -.033 & $-.030^{\star * *}$ & $-.033^{* * *}$ \\
\hline Densidad poblacional & .102 & $.115^{\star \star *}$ & $.102^{\star * \star}$ & $210^{* * *}$ & $.040^{* * *}$ & $.031^{* * *}$ \\
\hline Español como lengua materna & $.057^{* * *}$ & $.082^{* * *}$ & $.102^{\star \star *}$ & .210 & $.204^{* * *}$ & $.218^{\star * \star}$ \\
\hline Tamaño del hogar & $.05 / \%$ & $.054^{* * *}$ & $.057^{\star \star *}$ & .018 & $.016^{* *}$ & $.018^{* * *}$ \\
\hline Mujer jefe de familia & $200^{\star * *}$ & $-.040^{\star \star *}$ & $-.040^{\star * *}$ & $\begin{array}{l}-.005 \\
188^{* * *}\end{array}$ & -.005 & -.005 \\
\hline Edad de la mujer & $\begin{array}{l}.200^{n n} \\
002\end{array}$ & $.201^{* * *}$ & $.200^{* * *}$ & $\begin{array}{l}.188^{\prime} \\
042^{*}\end{array}$ & $.189^{* * *}$ & $.188^{* * *}$ \\
\hline Trabaja & .002 & .003 & .002 & .042 & $.043^{* * *}$ & $.042^{* * *}$ \\
\hline Nacida en el lugar & $\begin{array}{l}.0 \angle 0 \\
-252 * * *\end{array}$ & $.020^{\star \star *}$ & $.020^{\star \star *}$ & .052 & $.052^{\star \star *}$ & $.052^{\star \star \star}$ \\
\hline Número de hijos vivos & $099^{* * *}$ & $-.255^{\star \star *}$ & $-.252^{\star * *}$ & $125^{\star * *}$ & $-.415^{\star * \star}$ & $-.413^{* * *}$ \\
\hline Escucha radio & .099 & $.097^{* * *}$ & $.099^{* * *}$ & $\begin{array}{l}.120 \\
401\end{array}$ & $.123^{* \star *}$ & $.125^{\star \star \star}$ \\
\hline $\mathrm{R}^{2}$ & $(25,329)$ & .659 & .663 & $(25,230)$ & .399 & .401 \\
\hline (N) & & $(25,329)$ & $(25,329)$ & & $(25,230)$ & $(25,230)$ \\
\hline
\end{tabular}

1 Todas las ecorregions no-marítimas del Perú fueron incluidas. Se omite la intercepción, aunque estuvo incluida en las ecuaciones. $* \mathrm{p}<.05, * * \mathrm{p}<.01, * * * \mathrm{p}<.001$. 


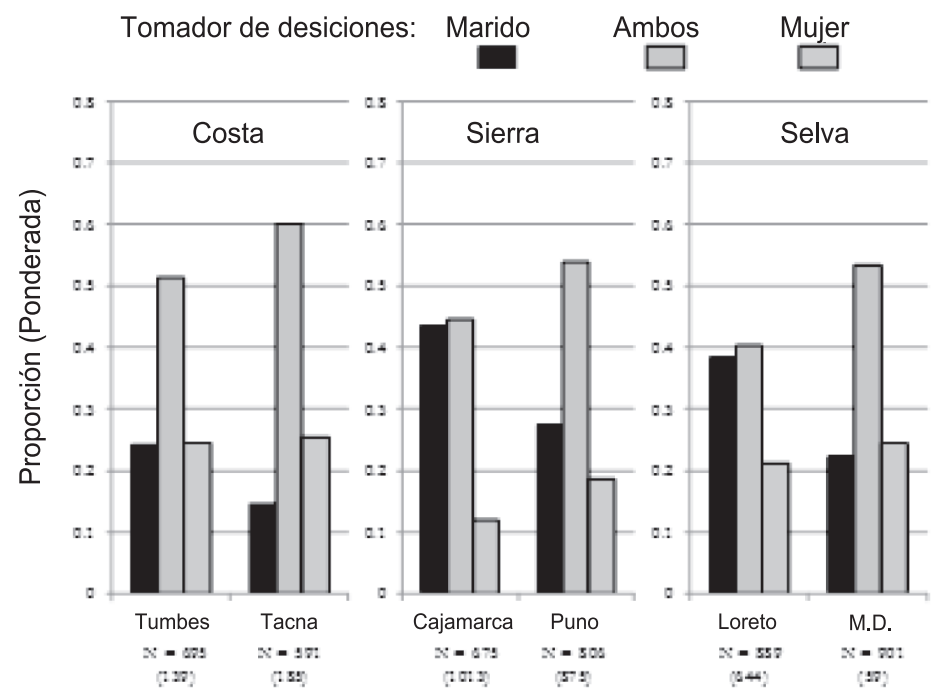

Figura 1. Proporción en que la informante, su marido, o ambos toman decisiones sobre grandes compras para el hogar en las regiones políticas más septentrionales y meridionales del Perú, por región natural $\mathrm{N}$ entre paréntesis es la ponderada. Fuente: León, 2011, Figura 1.

Figura 2. Ecoregiones del estudio. (1) El desierto del Pacífico es de un rango altitudinal de 1 a $1,000 \mathrm{msnm}$ y tiene una temperatura media de $10.6{ }^{\circ} \mathrm{C}$ debido a la fría Corriente de Humboldt (2) La estepa serrana comprende los flancos occidentales de los Andes (1,000 a 3,800 msnm); es la región más fría del Perú porque a los efectos de la Corriente de Humboldt se añaden los de la altura. (3) La puna de Brack cubre territorios de gran altura desde el Parque Nacional de Cutervo $(3,200 \mathrm{msnm})$ hasta las vecindades de glaciares por encima de los 5,200 msnm en el departamento de Tacna e incluye valles interandinos de menor altura. Su temperatura promedio es de $13.8^{\circ} \mathrm{C}$, pero presenta gran varación estacional y de día a noche, pudiendo alcanzar $-25^{\circ}$ en las noches de invierno del sur. (4) La cálida y húmeda yunga de Brack o ceja de selva comprende los flancos orientales de los andes, de $600 \mathrm{a}$ $3,500 \mathrm{msnm}$. Su temperatura promedio es de 20.1 ${ }^{\circ} \mathrm{C}$. (5) La Amazonía o selva baja, desde los 50 a los $600 \mathrm{msnm}$, tiene un clima tropical parecido al del África ecuatorial $\left(25.9^{\circ} \mathrm{C}\right)$. Fuente: León, 2012a, Fig 1.

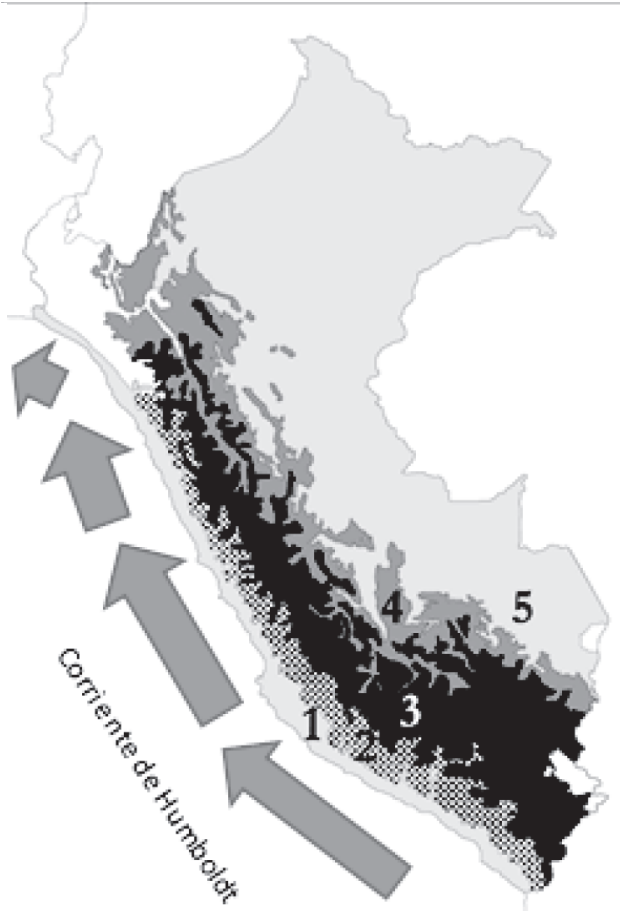




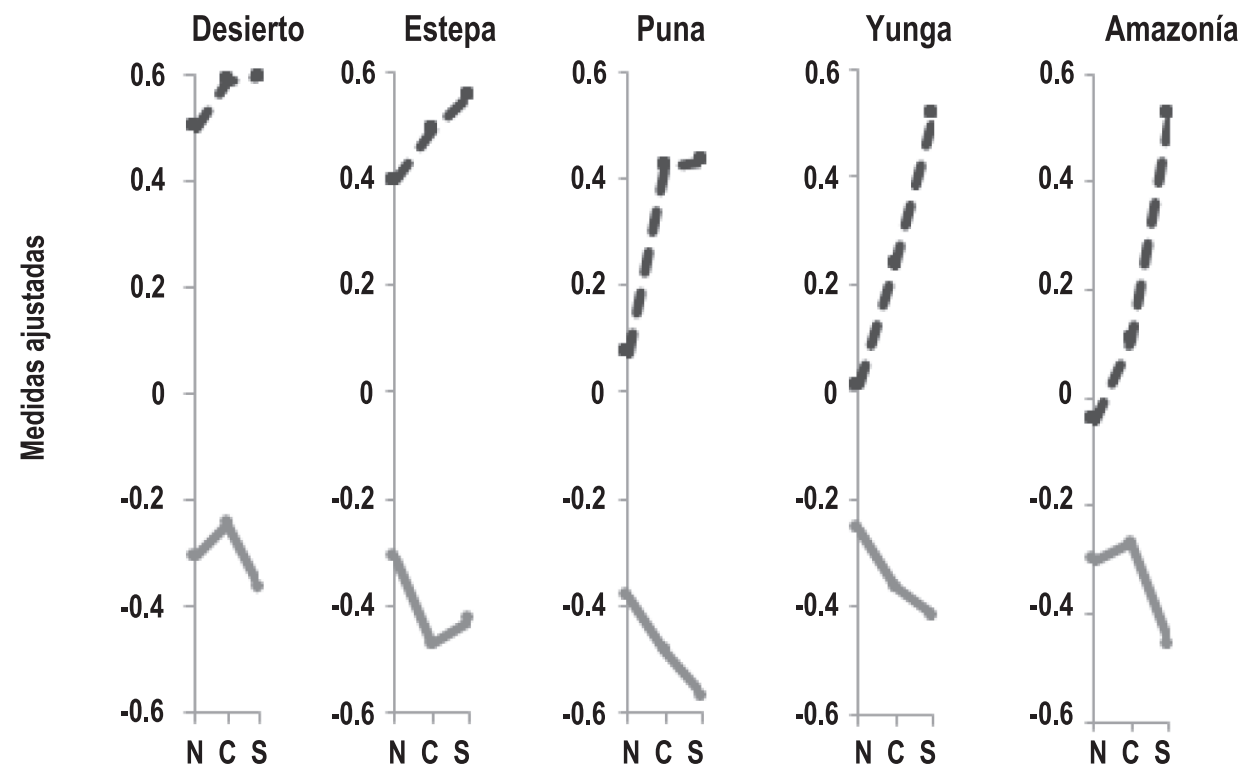

Figura 3. Medias de poder doméstico (Líneas interrumpidas) y deseo de hijos (Líneas sólidas) de la mujer ajustadas por 15 variables del modelo lineal general usado en el estudio, pornivel de latitud (N,C,S,) y ecoregión. Fuente: León, 2012a, Fig. 2.

$\begin{array}{ccccc}\text { Desierto } & \text { Estepa } & \text { Puna } & \text { Yunga } & \text { Amazonía } \\ \text { TL: }: p=.006 & \text { TL: } p=.001 & \text { TL: } p=.000 & \text { TL: } p=.000 & \text { TL: }:=.001 \\ \text { TC: } p=.865 & \text { TC: } p=.178 & \text { TC: } p=.083 & \text { TC: } p=.035 & \text { TC: } p=.001\end{array}$
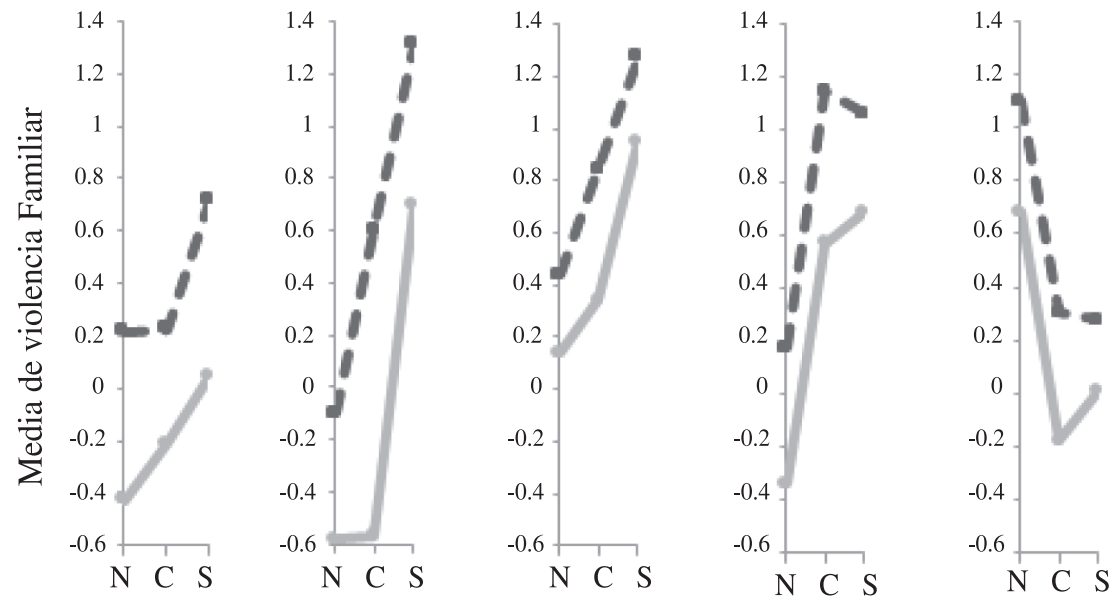

Figura 4. Medidas de violencia familiar sin ajustar (líneas interrumpidas) y ajustadas por 15 variables (líneas sólidas) según nivel de latitud (N,C.,S) y ecoregión, y significación de las tendencias lineales (TL) y cuadráticas (TC) de las medidas ajustadas. Fuente: León, 2012b, Figura 4 


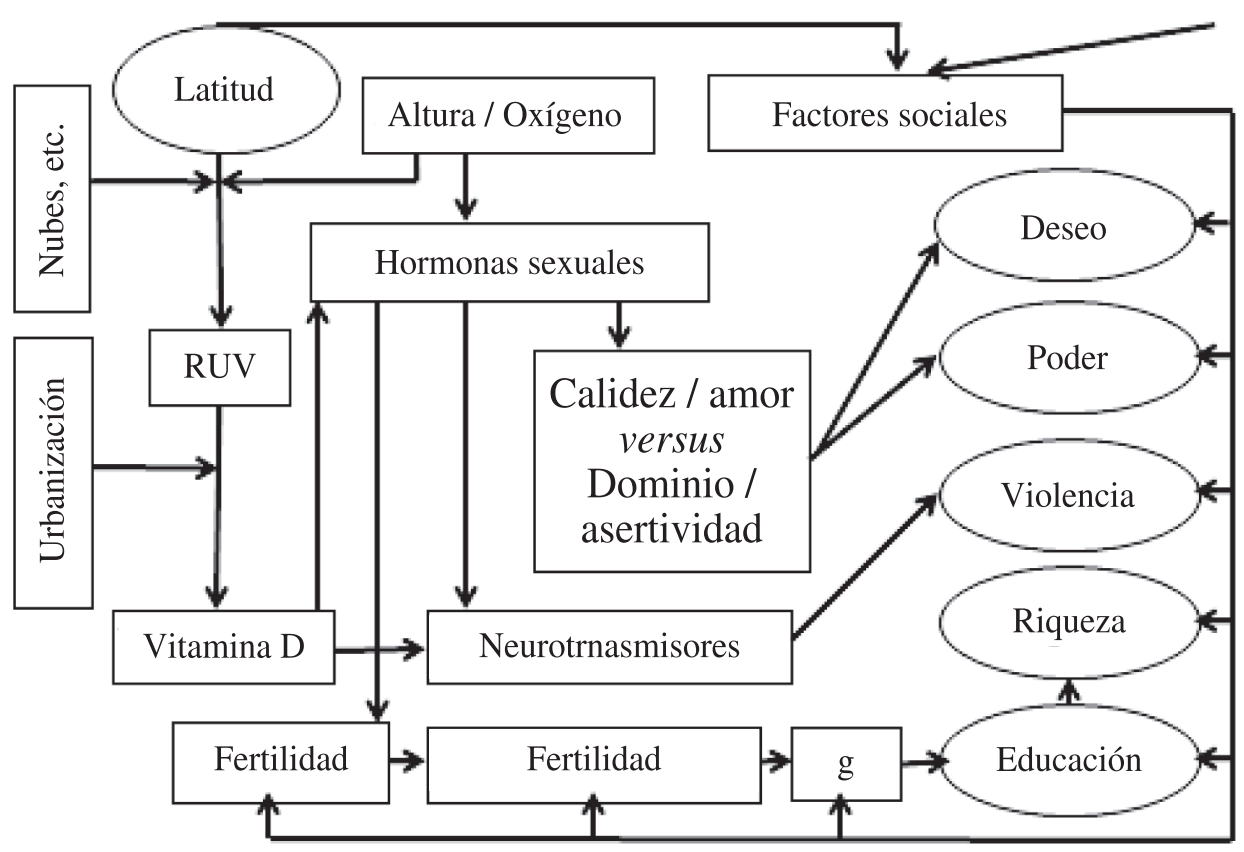

Figura 5. Teoría RUV sobre efectos de la latitud en poblaciones humanas. 